\title{
Radar studies at the mouths of ice streams D and E, Antarctica
}

\author{
ROBERT W. JACOBEL \\ St. Olaf College, Northfield, MN 55057, U.S.A. \\ ROBERT BINDSCHADLER \\ NASA Goddard, Greenbelt, MD 20771, U.S.A.
}

\begin{abstract}
Ice thickness measurements have been carried out at the mouths of ice streams D and E, West Antarctica using a surface-based impulse radar. These studies have been undertaken as a part of the continuing effort to understand the state of the West Antarctica ice sheet and its response to climate change. Thickness measurements will be used in the mass balance calculation currently in progress and to better understand features in the surface topography seen at low angle sun illumination in the satellite imagery. Results show that the discharge areas of ice streams D and E are thickening by approximately $1 \mathrm{~m}$ per year, and thus that these ice streams are probably loosing mass. Aperiodic wavelike features in the surface topography are described which pose interesting questions about migration of the grounding line and ice-stream dynamics.
\end{abstract}

\section{INTRODUCTION}

Surface-based radar studies were conducted at the mouth of ice streams D and E, West Antarctica during the 199192 field season as a part of the continuing effort to understand the state of the West Antarctica ice sheet and its response to climate change. The concern that marine ice sheets may be inherently unstable has led U.S. glaciologists to focus attention on the major ice streams which feed the Ross Ice Shelf. Collectively, these investigations have been known as the Siple Coast Project, and specific goals have been articulated (Whillans and Alley, 1991). Chief among these have been a determination of the configuration and net mass balance of the ice streams and the physical controls of ice flow in the region.

To that end, radar studies have been utilized in a number of investigations on the ice streams to sense remotely ice thickness (Shabtaie, and others, 1987; Retzlaff, and others, in press), conditions at the bed of the ice (Bentley and others, 1990; Jacobel and others, in press), the burial depth of crevasses (Bentley, and others, 1990), and the folding of internal layers (Jacobel and others, 1990, in press). In the present study, radar has been used to produce an ice thickness profile across the mouth of ice streams D and E (Fig. 1) to aid in the determination of mass balance for these two ice streams. In addition, radar profiles were conducted to better understand features in the surface topography seen in the satellite imagery.

\section{SYSTEM AND DATA ACQUISITION}

The system used was a short-pulse radar operating at a center frequency of $2 \mathrm{MHz}$, as described by Jacobel and others (1988). Modifications since that report include a PC-based data acquisition system allowing higher data rates, and the use of color displays in the field to aid in determining the location of subsequent profiles. The system with operator was towed on a Nansen sled by a skidoo moving typically at $4 \mathrm{~m} \mathrm{~s}^{-1}\left(15 \mathrm{~km} \mathrm{hr}^{-1}\right)$, and data were usually acquired at a density of one waveform every ten meters. Digitized waveforms were recorded with 1024 samples per waveform at 16 bit resolution, and utilized stacking (adding) of 256 waveforms to improve the signalto-noise ratio. Altogether approximately 25 megabytes of data were collected, corresponding to $110 \mathrm{~km}$ of total surface travel.

The base camp location ("Washington," Fig. 1) was chosen to be near the suspected grounding line of the ice streams and also proximate to the train of waves in surface topography beginning upstream of the camp and flowing past it just to the north. A transverse profile oriented approximately north to south was acquired for the mass balance calculation, and follows a line of stakes surveyed using the GPS satellite system. This line was terminated at both ends by heavy crevassing which can be seen in the Landsat mosaic image, Figure 1. Shorter profiles were acquired northeast of the base camp ("Bline") to study a region of grounded ice, and westnorthwest ("W-line") to study the wavelike features 


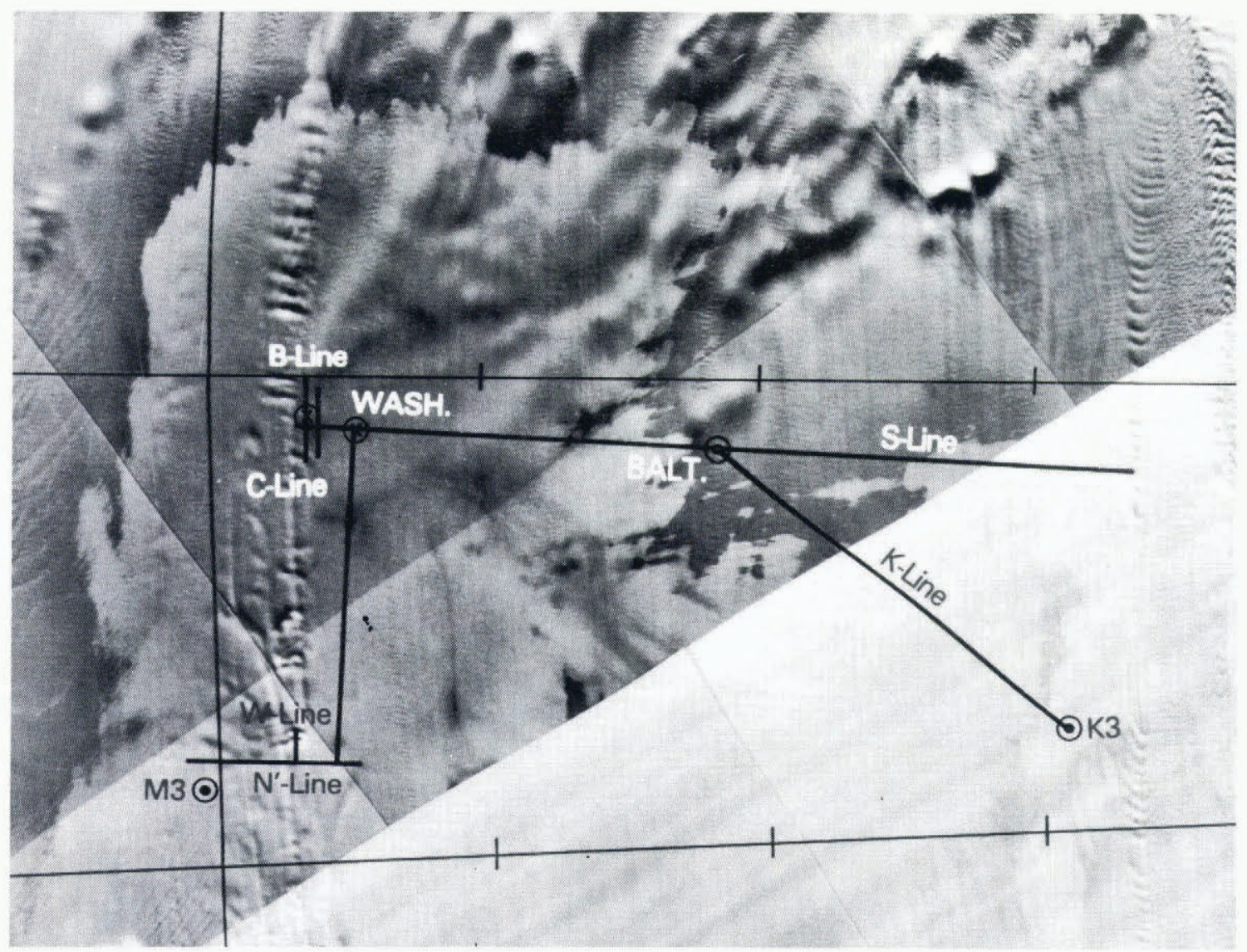

Fig. 1. Landsat Thematic Mapper image of the confluence of ice streams $D$ and $E$ near the grounding line. Camp locations and profile lines are indicated, as well as RIGGS stations K3 and M3.

mentioned above. In addition, radar soundings were taken at two former RIGGS sites, K3 and M3.

A constant midpoint profile (CMP) was done near the base camp to determine average wave velocities through the ice/firn column. Results show a wave speed of $175 \pm 1 \mathrm{~m} \mu \mathrm{sec}^{-1}$ and a thickness of $798 \pm 6 \mathrm{~m}$. This velocity is used in all subsequent calculations of ice thickness unless otherwise noted. The value obtained agrees well with previous determinations near this area made by Jiracek and Bentley (1971).

Radar profiles presented in this paper have been generated as color plots with two-way echo time on the vertical axis and distance along the surface represented horizontally. An approximate depth scale has been added at the right margin assuming the wave speed above and echoes arising from nadir reflection. Echo amplitude is depicted in a color scale with high value (darker colors) for the positive phase and low value (lighter colors) for the negative. Thus an approximately sinusoidal echo wavelet appears as a dark-light couple in the black and white reproduction shown here. Phase information is therefore well preserved, but amplitude differences are less easy to see in the converted grey scale.

\section{RESULTS AND DISCUSSION}

The $80 \mathrm{~km}$ long, north-south profile across most of the ice stream mouth shows the ice to be floating. That is, the minor rises in surface topography are supported at depth by greater ice thickness, indicating hydrostatic equilibrium. Average ice thickness is $800 \mathrm{~m}$ with the largest variations about $\pm 25 \mathrm{~m}$ from this value. While results from the mass balance calculation will not be available until the profile is resurveyed in 1993-94, we can at this time compare ice thickness with two stations occupied by the RIGGS survey in 1974-75. Our ice thickness values at both sites $\mathrm{K} 3$ and M3 are $775 \pm 5 \mathrm{~m}$, while the RIGGS values obtained were $741 \pm 10 \mathrm{~m}$ (Robertson and Bentley, 1990). However their thickness values were calculated using a slightly different wave velocity, and so travel times must be compared directly.

Comparing travel times and using our velocity value measured at the nearby camp to convert the difference to ice thickness, the result is an increase in ice thickness of $14 \pm 11 \mathrm{~m}$ over the 16 years. This correction of the RIGGS data (from $741 \mathrm{~m}$ to $761 \mathrm{~m}$ ) causes closer agreement between the radar-determined depths at stations K3 and M3 and the seismic-determined depths ( $755 \mathrm{~m}$ at $\mathrm{K} 3$ and $762 \mathrm{~m}$ at M3). While instrumental error cannot be ruled out completely, the above evidence provides support for our contention that the ice thickness has increased. Additional supporting evidence comes from the calculations of Shabtaie and Bentley (1987, Table $2 \mathrm{C}$ ) that ice streams $\mathrm{D}$ and $\mathrm{E}$ are both in negative mass balance and the calculations made by Bindschadler (in press) of thickening in the mouth of ice stream B at rates similar to our results.

Figure $2 \mathrm{a}$ is an $8 \mathrm{~km}$ long longitudinal profile to investigate a suspected region of grounded ice seen in the satellite imagery northeast of the base camp, ("B-line", Fig. 1). The profile shows a nearly constant ice thickness of $800 \mathrm{~m}$ with weaker reflectors above and below this 


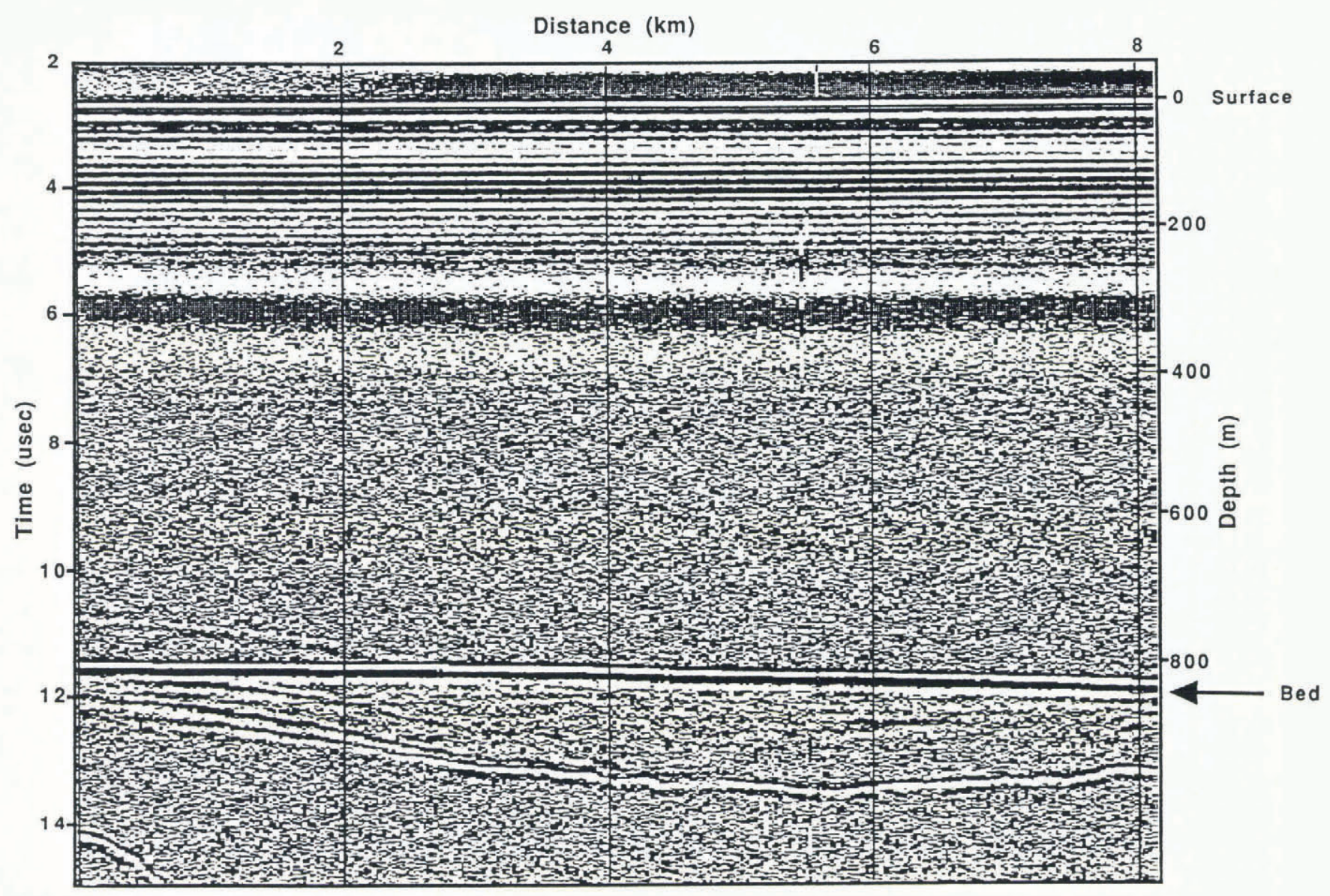

a

Ice Flow

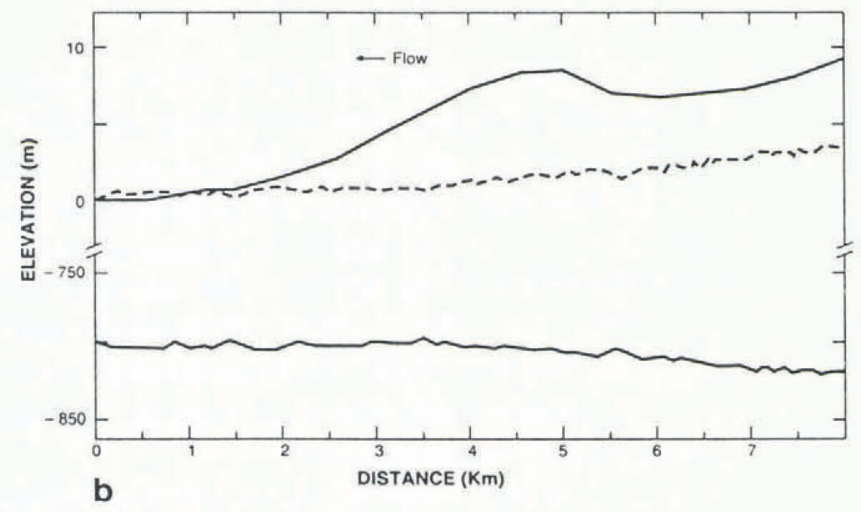

level. Surface leveling done along the profile shows that the upstream end rises about $10 \mathrm{~m}$ above the starting point, with an intermediate bump at km 4.5 of about $8 \mathrm{~m}$. Figure $2 \mathrm{~b}$ shows the surface elevation along the profile relative to the start, and the bed depth (surface elevation minus ice thickness) relative to the same datum. The dashed line is the hydrostatic surface computed from 0.1 times the ice thickness, that is the surface which would exist if the ice were afloat. This has been adjusted to correspond to the measured surface at the downstream end, thus providing an indication of areas which are out of balance. From the figure it can be seen that the bumps at $\mathrm{km} 4.5$ and 8 are about $7 \mathrm{~m}$ above hydrostatic equilibrium, and that much of the upper portion of this profile is slightly out of balance as well. To put this into thickness terms, an additional $70 \mathrm{~m}$ of ice thickness would be required to support the excess mass in the areas of these bumps. Our conclusion is that at these bumps, the ice is
Fig. 2. (a) Radar profile of the "B-line" showing ice thickness and several surface crevasses running approximately parallel to the profile. (b) Surveyed surface topography and bed depth relative to the starting coordinate for the same profile. Dashed line indicates the hydrostatic surface adjusted so that the ice at the downstream end is floating. Ice surface upstream is up to $7 \mathrm{~m}$ above the hydrostatic level, indicating regions of grounding.

physically in contact with the bed which supports them, and therefore that we can recognize other areas of grounded ice in satellite imagery based on this study.

The profile in Figure 2 runs through a region of crevasses oriented approximately along the direction of flow and thus nearly parallel to the profile. This crevassed region begins just south of the profile, and crevasses increased in density through the study area and on northward. At least one large opening was discovered, but most crevasses were identified by long hairline cracks in the snow surface running parallel to the profile, which when probed and excavated proved to be crevasses as well. The hyperbolic echo at the left edge of Figure 2 is undoubtedly a crevasse off to the side of the profile and oriented across the flow. The more continuous reflectors at about the same distance as the bed are likely to be two or more crevasses oriented parallel to the profile. The brightest of these continues across the entire profile and is 


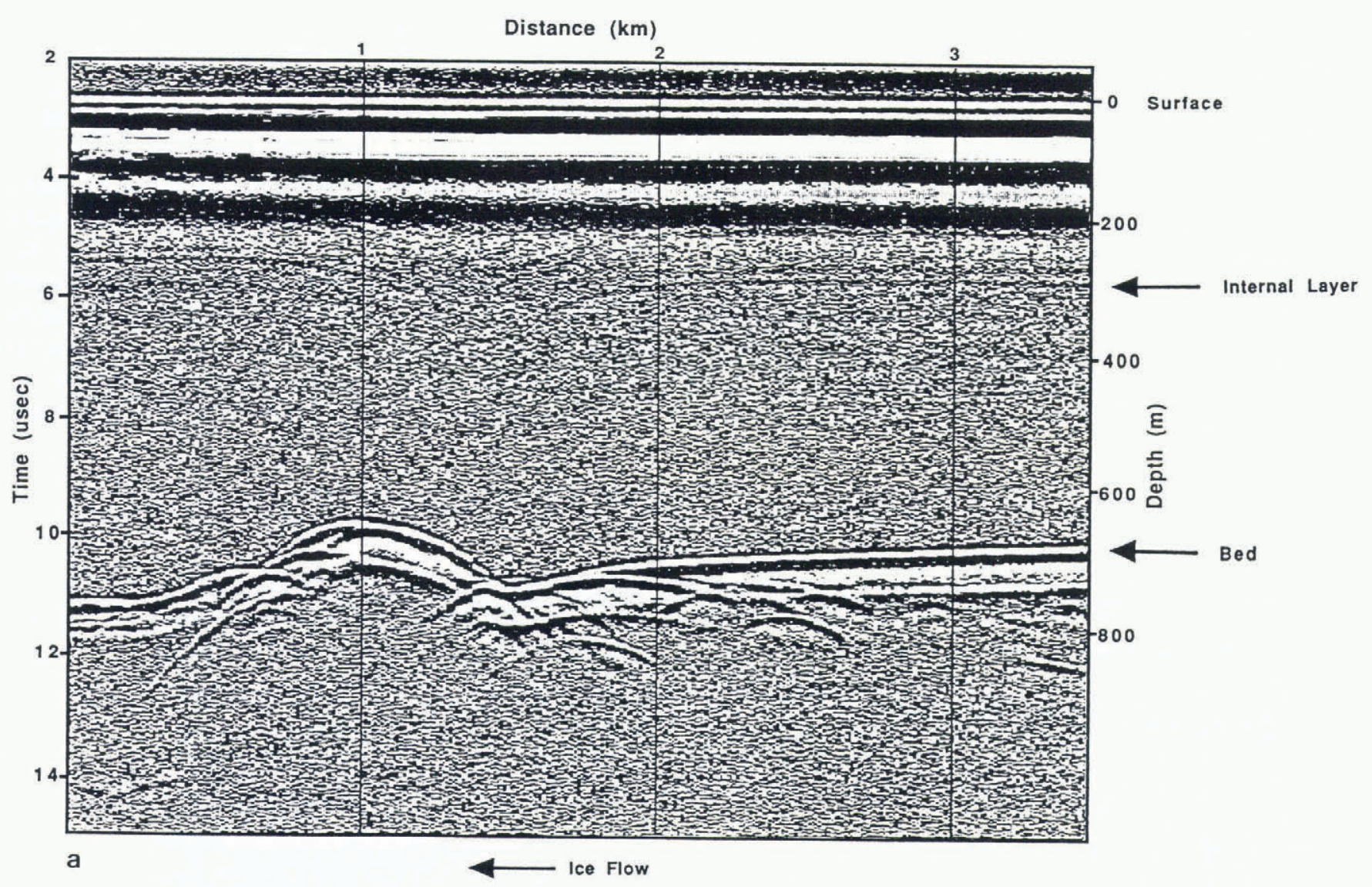

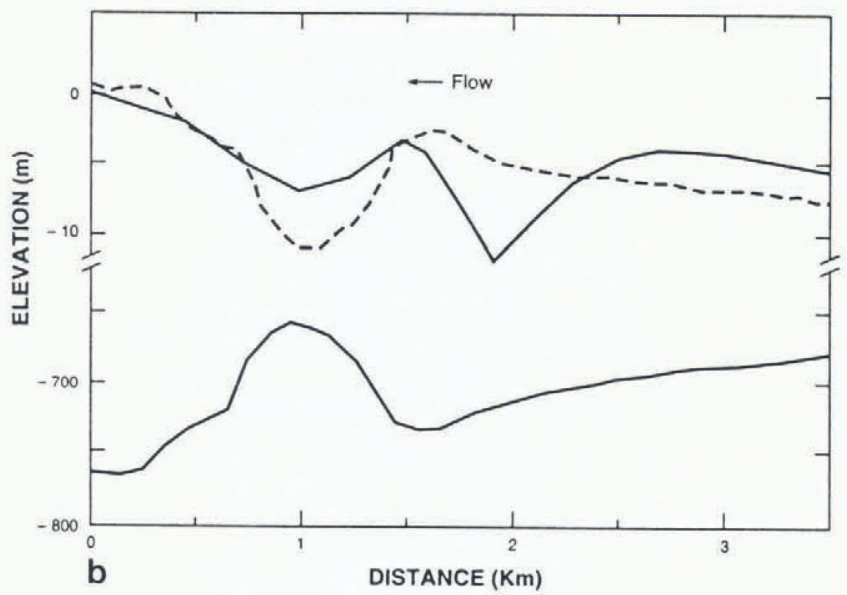

harder to understand. It may be a single long crevasse, or series of crevasses with the same strike and distance.

Figure 3 shows our measurements along the longitudinal "W-line" downstream from the base camp (Fig. 1). This line was established to study the wave-like feature seen in the Landsat image. Because the image was collected on 5 February 1990 approximately two years before the field measurement, the wave-like feature in Figure 1 appears approximately $1 \mathrm{~km}$ upstream of the profile. The image shows that the wave studied is only one of a number of similar features which occur aperiodically along a narrow flowband. The source region for these features appears to be the grounding line area approximately $70 \mathrm{~km}$ upstream.

Figure $3 \mathrm{a}$ presents the profile of ice thickness. There are a large number of bottom crevasses, the largest of which defines a region of thinner ice near $\mathrm{km} \mathrm{1.0.} \mathrm{Also,} \mathrm{an}$ internal layer can be seen across nearly the entire profile
Fig. 3. (a) Radar profile of the " $W$-line" showing ice thickness across one of the wave features downstream of the base camp. Crevasses at the base of the floating ice are evident, particularly in conjunction with places where ice thickness decreases. (b) Surveyed surface topography and bed depth relative to the starting coordinate for the same profile. Dashed line indicates the hydrostatic surface which shows that portions of the wave feature are out of hydrostatic equilibrium, particularly near $\mathrm{km} 1.9$ where the measured surface is well below hydrostatic. at about $280 \mathrm{~m}$ depth, that dips markedly at $\mathrm{km} 1.4$. Figure $3 \mathrm{~b}$ presents the corresponding profiles of surface elevation as measured by optical survey and calculated from the ice thicknesses assuming hydrostatic equilibrium, and the bed profile.

These results pose a number of interesting questions. It is clear from Figure $3 \mathrm{~b}$ that this section of ice is not in hydrostatic balance. Both the trough at $\mathrm{km} 1.0$ and the crest at $\mathrm{km} 1.5$ are matched by signatures in the ice thickness profile but the magnitudes of the "wave" in the measured and calculated profiles do not agree well. At least a part of this disagreement comes from our radar thickness estimates which have not been corrected for distortion due to the finite beamwidth of the antenna. This produces the hyperbolic echo patterns seen along the bed, and tends to broaden bumps and underestimate dips. Thus the fit of measured surface features by the hydrostatic curve will not be exact, especially for shorter 
wavelength features. However, the peak-to-trough amplitude of the wave should match that seen in the hydrostatic surface if the ice is in equilibrium, and it does not.

It is possible that this difference is the result of relatively larger snow accumulation in the trough which would cause a lower column-averaged density and an underestimate of the surface elevation. To quantify this hypothesis, if the feature were formed at the grounding line, 175 years would have passed and approximately $44 \mathrm{~m}$ of snow would have accumulated by the time the feature reached its present position. A redistribution of snow that caused a $10 \%$ difference in the density of the upper $44 \mathrm{~m}$ of snow would be sufficient to explain the apparent mis-match shown in Figure 3b. Therefore this portion of the W-line could be in hydrostatic balance.

The longevity of such a feature can be investigated in simple terms by considering the evolution of two adjacent floating ice columns, one $740 \mathrm{~m}$ thick and the other $660 \mathrm{~m}$ thick. The upper surface of these two columns would differ by approximately $7.4 \mathrm{~m}$ (the difference between the crest and the deeper trough). Using the relationship that the horizontal strain rate of unconfined floating ice varies with the third power of the ice thickness, and assuming no transverse spreading of the ice (so the rate of vertical strain thinning equals the horizontal strain rate), after

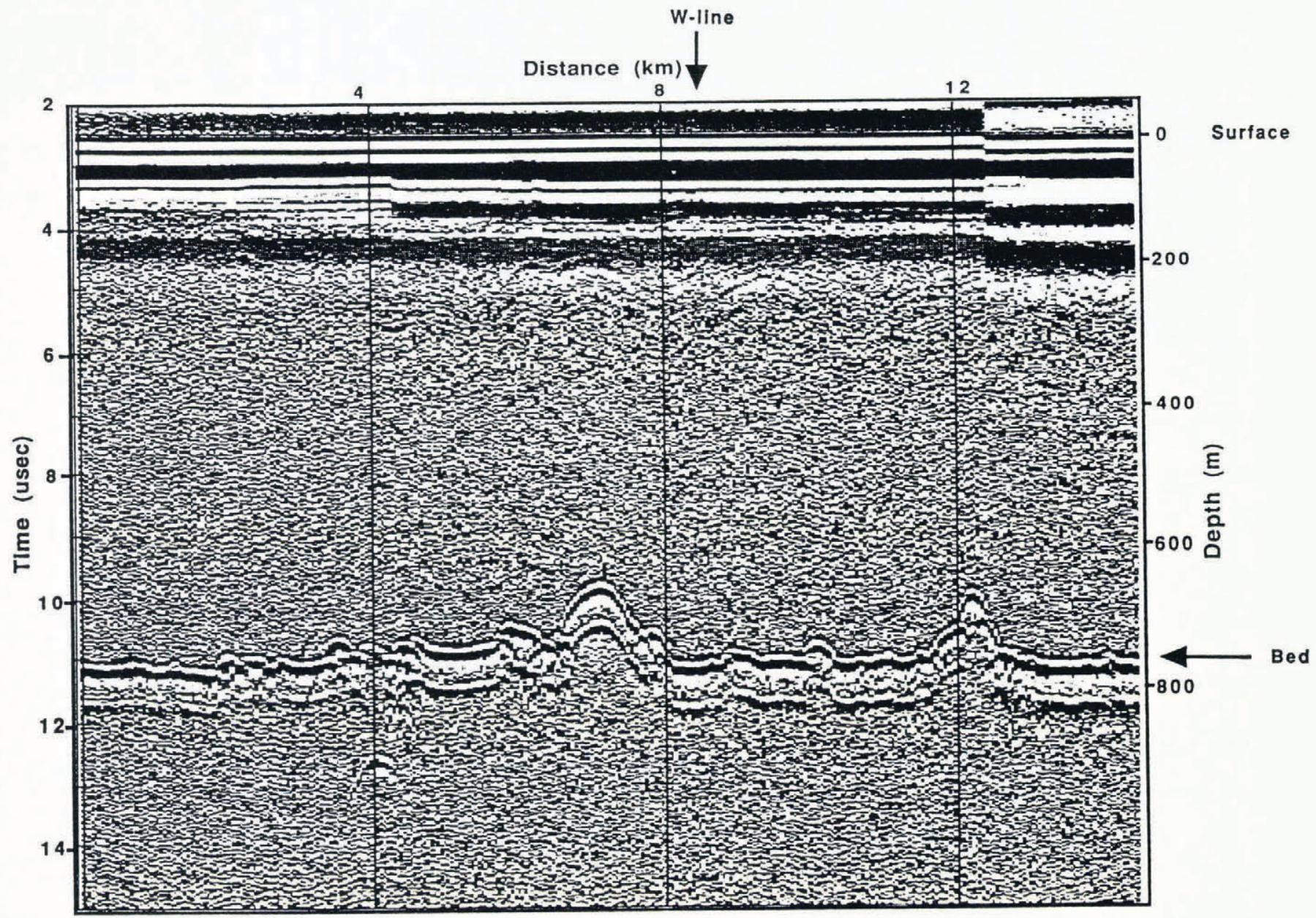

Ice Flow $\odot$

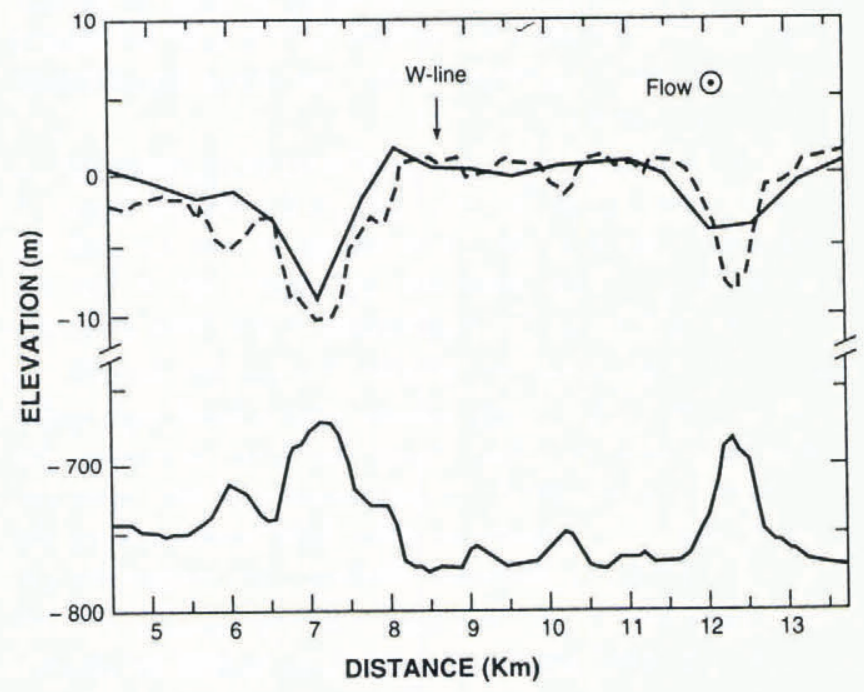

Fig. 4. (a) Radar profile of the " $\mathcal{N}$ '-line" showing ice thickness transverse to the wave feature in Figure 3. (b) Surveyed surface topography and bed depth for a portion of the same profile with vertical coordinates relative to the $W$ line in Figure 3. Dashed line indicates the hydrostatic surface showing areas of minor imbalance. 
100 years the difference in elevation between the upper surfaces of these two ice columns would decrease by only $1 \mathrm{~m}$. Thus, it is quite likely that this feature was generated $70 \mathrm{~km}$ upstream at the grounding line and is slowly decaying.

The region most out of balance in Figure $3 \mathrm{~b}$ is the deeper of the two surface troughs at $\mathrm{km} 1.9$ that has no matching signature in the ice thickness profile. This implies that there must be vertical shear stress within the ice contributing to a bending moment in the adjacent ice. This bending may be partially responsible for the region upstream of this trough appearing to be above hydrostatic. If this feature is characterized as a block of ice $500 \mathrm{~m}$ long and depressed $6 \mathrm{~m}$ below hydrostatic, then the average shear stress along the vertical boundaries of the block (where it contacts the $700 \mathrm{~m}$ thick ice shelf) is approximately $0.2 \mathrm{bar}(20 \mathrm{kPa})$. If this is the dominant stress in the ice then the simplified flow law can be used along with a suitable value of the stiffness parameter for the Ross Ice Shelf $\left(\mathrm{A}=0.016 \mathrm{bar}^{-3} \mathrm{a}^{-1}\right.$; from Thomas, 1973) to calculate that the vertical shear strain rate would be approximately $10^{-4} \mathrm{a}^{-1}$ and the vertical motion in the center of the column would be $0.016 \mathrm{~m} \mathrm{a}^{-1}$. Thus, it is quite feasible that even this feature, too, could have been generated at the grounding line.

Also apparent in the radar data is an internal layer. It occurs at approximately $280 \mathrm{~m}$ depth at the upstream end of the profile, dips rather sharply to below $300 \mathrm{~m}$ depth at $\mathrm{km} \mathrm{1.5,} \mathrm{then} \mathrm{returns} \mathrm{to} \mathrm{a} \mathrm{depth} \mathrm{of} 230 \mathrm{~m}$ downstream. The annual accumulation rate in this region of West Antarctica ranges between 0.1 and $0.2 \mathrm{~m} \mathrm{a}^{-1}$ (ice equivalent) so the age of the ice at these depths is well over a thousand years and it accumulated well upstream of the grounding line and possibly even upstream of the entire ice stream. The position of the dip corresponds to the crest in the surface feature and suggests that the contortion of the internal layer is related to the formation of the wave-like feature.

Figure 4 presents similar data of ice thickness and surface topography along the adjoining, but transverse "N'-line", (Fig. 1). The positions of the two major surface depressions at $\mathrm{km} 7$ and $\mathrm{km} 12$ match the positions of the two regions of thinner ice. Figure 1 shows that the larger feature at $\mathrm{km} 7$ is associated with a long longitudinal trough in the imagery while the smaller feature is isolated and not associated with any extended trough.

The larger dip at $\mathrm{km} 7$ is clearly in hydrostatic balance (Fig. 4b) but the smaller depression at km 12 does not match the hydrostatic prediction well. At least a part of the mismatch may be due to estimating the ice thickness from the apex of the hyperbolic echo near the top of the bump which may well be produced by a crevasse extending up into the ice. Choosing a less sharply peaked bed bump will bring the hydrostatic curve into better agreement with the measured surface profile.

Shorter wavelength features of the ice thickness and the surface elevation are not well correlated, in part for the reasons described above. However this is true even for the shallow but broad surface trough at $\mathrm{km} 9$ to 10 which is easily seen in Figure 1. Figure $4 \mathrm{~b}$ shows that this trough is bounded on either side by thinner ice; but, directly underneath the ice is too thick to be in hydrostatic balance. From the calculations above, however, local unequilibrated zones should not be a surprising result given the lower magnitude of these features and their small spatial extents.

These data raise interesting questions about how these features were formed, and how they are retained in the ice. Our working hypothesis is that they are produced at the grounding line by some as yet not well understood process. Our calculations show that it is reasonable for folds which are in hydrostatic equilibrium to persist for several hundred years, and also for features which are marginally out of balance to be maintained over similar periods. But it is not clear why adjacent parts of a fold feature should be in and out of balance. If the folds are produced at a grounding point, perhaps the ice just downstream adjusts so as to be in hydrostatic balance, while upstream areas are constrained by the bed, and when released remain out of balance.

While it is not difficult to conceive of mechanisms which can produce changes in ice thickness and topography (rises in the bedrock, or changes in basal friction, for example), it is more difficult to explain in any detail how the observed waves are created. Ice shelf "pressure rollers" have been analyzed as creep instabilities by Collins and McCrae, 1985, who argue in favor of this mechanism over elastic buckling which requires $10^{5}$ times larger forces. However the pressure rollers they considered are standing wave patterns, fixed with respect to the bed below the ice sheet. In contrast, the waves we have observed move with the ice sheet flow, and thus are not produced by either of these mechanisms.

What is clear, then, is that time-dependent mechanisms must be operating for them to be propagated downstream, and to appear aperiodically. Presumably this gives clues to behavior at the grounding line and ice stream dynamics, perhaps indicating shifts of this zone in time. We are hopeful that the strain rates we will obtain from a resurvey of the area of the wave feature in 1994 will provide a fuller understanding of the phenomena.

\section{CONCLUSIONS}

Surface-based ice radar profiling with a small sledmounted system has been useful in a number of studies on the ice streams. Part of the system's utility has been the facility it provides for viewing profile results immediately in the field, enabling us to form hypotheses and make informed decisions about subsequent studies based on what has been seen. While we await the results of the mass balance study, preliminary indications are that the discharge of ice streams D and $\mathrm{E}$ are causing thickening, and thus these ice streams are likely losing mass. A number of features identified in the satellite imagery have been explored with the radar and found to be related to processes occuring at depth, some of them not wellunderstood. These features give information about ice stream dynamics which is important to understanding the behavior of the West Antarctica ice sheet.

\section{ACKNOWLEDGEMENTS}

We express our thanks to Patrica Vornberger and Ted Scambos of NASA for invaluable collaboration and 
assistance with the field work, and to Kristen Nelson of St Olaf College for her work on the data analysis. We thank the U.S. National Science Foundation which supported this work with grants DPP-9104417 to St Olaf College, and DPP-9018127 to NASA Goddard.

\section{REFERENGES}

R. B. Alley and I. M. Whillans. 1991. Changes in the West Antarctic ice sheet. Science, 254(5034), 959-963.

Bentley, C. R., R. Retzlaff, A. N. Novick and N. Lord. 1990. Analysis of radar data. Antarct. J. U. S., 25(5), 88-90.

Bindschadler, R. A. In press. Siple Coast Project research of Crary ice rise and the mouths of Ice Streams B and C, West Antarctica: review and new perspectives. $\mathcal{J}$. Glaciol.

Collins, I. F. and J. R. McCrae. 1985. Creep buckling of ice shelves and the formation of pressure rollers. $\mathcal{J}$. Glaciol., 31(109), 242-252.

Jacobel, R. W., S. A. Anderson and D. Rioux. 1988. A portable digital data acquisition system for surfacebased ice-radar studies. F. Glaciol., 34(118), 349-354.

Jacobel, R. W., A. M. Gades, D. L. Gottschling, S. M. Hodge and D. L. Wright. In press. Interpretation of radar-detected internal layer folding in West Antarctic ice streams. 7. Glaciol.

Jacobel, R. W., S. Hodge and D. Wright. 1990. Studies of internal layering and bedrock topography on Ice Stream C, West Antarctica. Antarct. F. U.S., 25(5), 82-85.

Jiracek, G. R. and C.R. Bentley. 1971. Velocity of electromagnetic waves in Antarctic ice. Antarct. Res. Ser., 16, 199-208.

Retzlaff, R., N. Lord and C.R. Bentley. In press. Airborne-radar studies: Ice Streams A, B, and C, West Antarctica. 7. Glaciol.

Robertson, J. D. and C. R. Bentley. 1990. Seismic studies on the grid western half of the Ross Ice Shelf: RIGGS I and RIGGS II. Antarct. Res. Ser., 42, 55-86.

Shabtaie, S. and C. R. Bentley. 1987. West Antarctic ice streams draining into the Ross Ice Shelf: configuration and mass balance. 7. Geophys. Res., 92(B2), 1311-1336.

Shabtaie, S., I. M. Whillans and C. R. Bentley. 1987. The morphology of ice streams A, B, and C, West Antarctica, and their environs. 7. Geophys. Res., 92(B9), 8864-8883.

Thomas, R. H. 1973. The creep of ice shelves: interpretation of observed behavior. F. Glaciol., 12(64), 55-70.

The accuracy of references in the text and in this list is the responsibility of the authors, to whom queries should be addressed. 